\title{
Flourishing in a fragmented world
}

'Modernity partitions each human life into a variety of segments, each with its own norms and modes of behaviour' (MacIntyre, 1982). In his landmark book After Virtue (1982), Alasdair MacIntyre argued that fragmentation of our lives is a feature of our society.

Work and leisure, public and private life, are seen as completely separate, each with different values and moral rules. There is much discussion about how to achieve 'work-life balance,' although work, like relationships and activities undertaken solely for pleasure, contributes to a full and flourishing life.

MacIntyre doesn't talk much about health and illness, but Sontag (1978) has vividly described the deep division we make between the kingdom of the sick and the kingdom of the well. Yet those who work or research primary care know well that health (and therefore healthcare) and other aspects of life are intimately and complexly intertwined.

Several papers in this issue of the Journal illustrate this: our physical activity (Bohman, Mattsson and Borglin), the quality of our personal relationships (Williamson et al.) and other aspects of our lifestyle (Dickfos et al.) have a major impact on our health. The converse is also true; our health affects our relationships and how we live our lives. What we eat depends not only on our appetite, obviously linked to our health, but also our income, which is affected by our health because that affects our earning capacity (Chronic Poverty Research Centre, 2008) and thus the food choices available to us. Papers in this issue also remind us that the borders between health and illness and of individual diseases are fuzzy (Shivaji and Ford), as is the boundary of healthcare itself (Jarvis et al.) and even of what is medication (Melling).

We sometimes try to pretend these things are less complexly intertwined than they really are. I recently accompanied some GP trainees to a briefing on individual funding requests in the NHS. We were told that those responsible for these difficult decisions do not take account of psychological and social factors. As primary care clinicians are aware, in the messy reality of life this sort (C) Cambridge University Press 2015 of separation between healthcare and other aspects of life is rarely possible, realistic or just.

MacIntyre sees this partitioning of life as one aspect of a fundamental fragmentation of our values and moral theory since the Enlightenment, so that consequentialists and deontologists, realists and emotivists, stoics and existentialists cling to different fragments of a moral shipwreck. As we lack a shared moral vision and set of values our moral discussions are inconclusive. Those who believe that abortion should be freely available because woman have 'a right to choose' have no common ground with those who see the 'right to life' of the fetus as inviolable; whereas those who think each case should be decided according to which action leads to the greatest good for the greatest number can't see what all the fuss is about.

I recently attempted to apply MacIntyre's analysis to healthcare (Toon, 2014). It is surprising how well it fits. As well as the two conflicting moral theories of deontology, the rule-based fragment used by the GMC, NMC and HPC to guide those they govern, and consequentialism used by public health practitioners and NICE, healthcare uses several other fragmentary moral frameworks, each with its own incommensurable values. Political pressures lead to the NHS being seen in terms of consumerism, not treating patients but fulfilling the desires of consumers for convenience and choice - a set of values clearly implicit in the NHS Constitution (Department of Health, 2013). The growing role of management, and the place of law in our increasingly litigious and risk-averse society means that law and management often turn into legalism and managerialism - other fragments each with its own set of values that have an increasing influence on healthcare.

This fragmentation leads to confusion and incoherence. When a patient asks a clinician for something she does not believe to be helpful, does she give the patient what he wants (consumerism); follow strictly the obligations the GMC or NMC impose (deontology); appeal to the need to use public resources to achieve the greatest overall 
good (consequentialism) or follow the current guidelines (managerialism)?

Facing this sort of moral incoherence several times a day can lead to low morale and lack of a sense of direction. Moreover, many of these models make healthcare a zero-sum game. The more rights the patient has, the more duties are imposed on the clinician. The more consumer-patients get the more producer-clinicians have to provide.

MacIntyre suggests that the solution lies in a virtue ethic, in which people collaborate to produce the 'internal goods' that lead to flourishing. Virtue ethics does not suggest that we need to be moral saints or sanctimonious prigs who never do anything wrong, for that would not lead to flourishing but merely impose yet another burden on the long-suffering clinician. Virtue ethics argues that we should pay attention to the personal qualities such as courage, honesty, temperance and compassion that all of us, clinicians and patients alike, need in order to live flourishing lives. These qualities help us achieve the internal goods such as knowledge, understanding, happiness and flourishing, which are unlimited, unlike material goods, which are finite, so that our gain is someone else's loss.

At first sight this might sound optimistic, even idealistic, but when we think it through we find that in many ways looking at healthcare from MacIntyre's perspective is more practical as well as more coherent than our current moral muddle. It offers a vision of professionalism that might help move on a debate which in recent years has got rather bogged down. It offers a better vision of relationships between different professions and between clinicians and patients than the tribal rivalries and adversarial positions we so often see. In addition, it offers a vision of healthcare that can contribute to flourishing lives for patients, clinicians, managers and all the others engaged in the practice of healthcare; and surely in the end, flourishing lives are what we are all seeking.

Peter D. Toon GP Ethicist

\section{References}

Chronic Poverty Research Centre. 2008. Health and poverty linkages: perspectives of the chronically poor. Chronic Poverty Research Centre. Retrieved 27 March 2015 from http://www.chronicpoverty.org/uploads/publication_files/ CPR2_Background_Papers_Grant_05.pdf.

Department of Health. 2013. The NHS constitution for England. Department of Health. Retrieved 27 March 2015 from https://www.gov.uk/government/uploads/system/uploads/ attachment_data/file/170656/NHS_Constitution.pdf.

MacIntyre, A. 1982. After virtue, second edition. London: Duckworth.

Sontag, S. 1978. Illness as metaphor. New York: Farrar, Straus and Giroux. Retrieved 27 March 2015 from http://monoskop. org/images/4/4a/Susan_Sontag_Illness_As_Metaphor_1978.pdf.

Toon, P.D. 2014. A flourishing practice? London: Royal College of General Practitioners. 